\title{
Clinical Outcomes, Safety and Efficacy of Intrapleural Hyperthermic Chemotherapy for Thoracic Malignant Diseases with Pleural Effusion
}

\author{
Takanori Ayabe*, Masaki Tomita, Eiichi Chosa, Hiroki Mori, Kunihide Nakamura \\ Division of Thoracic and Breast Surgery, Department of Surgery, Faculty of Medicine, University of Miyazaki, \\ Miyazaki, Japan \\ Email: "tayabe@med.miyazaki-u.ac.jp
}

Received 11 January 2016; accepted 15 March 2016; published 18 March 2016

Copyright () 2016 by authors and Scientific Research Publishing Inc.

This work is licensed under the Creative Commons Attribution International License (CC BY).

http://creativecommons.org/licenses/by/4.0/

c) (i) Open Access

\section{Abstract}

Background: We have performed the cisplatin-based intrapleural hyperthermic chemotherapy (IPHC) for advanced lung cancer with pleural effusion and for malignant pleural mesothelioma (MPM). Retrospectively, the outcomes of the IPHC were evaluated. Methods: For 14 years from February, 2000 to February, 2014, we performed 14 cases of IPHC including 8 lung cancers (staged-IV) and 6 MPMs (staged-III: 5; IV: 1). We divided these cases in two groups; the lung cancer group (LC group) and MPM group, and assessed the perioperative factors, toxicities, and effectiveness. Results: The patient age averaged $66.5 \pm 11.1$ years old (11 males and 3 females). The pathology was 7 pulmonary adenocarcinomas, 1 pulmonary angiosarcoma, and 6 epithelial type MPMs. The regimens of the IPHC were CDDP $(300 \mathrm{mg})$ plus saline $(\mathrm{n}=12)$, CDDP $(100 \mathrm{mg})$ plus saline $(\mathrm{n}=1)$, and CDDP $(300 \mathrm{mg})$ plus distilled water $(\mathrm{n}=1)$. The operation and IPHC time was 204 \pm 70 and $59 \pm 19$ minutes, respectively. Intraoperative complication was observed in 2 lung injuries due to exfoliation of the pleural adhesion in the LC group. Blood loss was $292 \pm 365 \mathrm{ml}$. The postoperative complication, i.e., subcutaneous emphysema, was observed as grade 2 pulmonary fistula $(7.1 \%, 1 / 14)$, which was significantly observed in the LC group $(1 / 8,12.5 \%)$ compared to the MPM group $(0 / 8,0 \%)(p=0.040)$. The hematological toxicity of more than grade 3 was observed in only one case of anemia $(7.1 \%, 1 / 14)$ and in the LC group $(25 \%, 1 / 8)$. The grade 3 anemia $(25 \%, 1 / 8)$ and grade 2 neutropenia $(25 \%, 1 / 8)$ in the LC group were significantly observed compared to those in the MPM group $(0 \%, 0 / 6)$, respectively $(p=0.040)$. The postoperative cytology of the malignant cells in the pleural effusion resulted in the negative $(n=6)$, positive $(n=7)$, and not evaluated $(n=1)$, and the control rate was calculated to be $46.2 \%(6 / 13)$. There was no significant difference between the two groups $(p=0.083)$, that is, $42.9 \%(3 / 7)$ in the LC group and

\footnotetext{
"Corresponding author.
} 
$50.0 \%(3 / 6)$ in the MPM group. For the postoperative amounts of the pleural effusion, reduction $(n=10)$, unchanged $(n=3)$, and not evaluated $(n=1)$, the control rate was calculated to be $76.9 \%$ $(10 / 13)$. There was a significant difference between the two groups $(p=0.042)$, that is, $71.4 \%$ $(5 / 7)$ in the LC group and 83.3\% (5/6) in the MPM group. Conclusion: The IPHC treatment resulted in no major complications, and fewer adverse events of more than grade 3 . The outcome of the IPHC was safety, and a very effective control of the malignant cells and pleural effusion.

\section{Keywords}

Intrapleural, Hyperthermic, Chemotherapy, Lung Cancer, Mesothelioma, Thoracic Malignancies

\section{Introduction}

In Japan, seventy thousand lung cancer patients have died every year; the number of dead was mostly due to malignancies, $80 \%$ of which consisted of non-small cell carcinoma. In recent years, the Japanese population has become aged and the number of elder lung cancer patients has increased.

By the seventh edition of the tumor-node-metastasis (TNM) staging system for lung cancer [1], an advanced lung cancer with pleural dissemination and/or malignant pleural effusion was defined as M1a, which is described as "tumour with pleural nodules or malignant pleural/pericardial effusion", displayed as stage IV the same as advanced cases with a distant metastasis. This type of lung cancer is considered to have no indication for surgery, aggressive therapy should be difficult due to the poor performance status and poor quality of life (QOL), and an effective treatment has not yet been established. Generally, the prognosis should be worse, as only a few optional treatments, such as cytotoxic systemic chemotherapy and molecular-targeted drug treatment are performed.

Based on the basic scientific study about the anti-cancer effect of intrapleural hyperthermic chemotherapy (IPHC), our study group has performed the IPHC treatment since 1980. From 1988, our IPHC was indicated for lung cancers with dissemination with a resectable case of primary lung cancer with no lymphatic metastasis and no distal metastasis, which was possible for single-lung ventilation under general anesthesia. Our conventional IPHC treatment has been performed in clinical practice [1]-[5].

Regarding the benefits of the IPHC treatment, in addition to the tumor-cytotoxic effects with hyperthermic escalated efficacy, the palliation of dyspnea and improvement of the QOL are expected, that is, the control of the pleural effusion, shortening of the thoracic drainage period, lengthening the outpatient palliative therapy at home, and preserving the patient's QOL.

We have summarized our 14-year experience and retrospectively evaluated our conventional IPHC treatment for thoracic malignancies (lung cancers and malignant pleural mesothelioma) and now report the clinical outcome about the perioperative factors, complications, adverse events, effectiveness, and safety.

\section{Patients and Methods}

\subsection{Patient Characteristics}

For 14 years from February, 2000 to February, 2014, we performed 14 cases of conventional IPHC treatment, which consisted of 8 lung cancers and 6 malignant pleural mesotheliomas (MPM). The pathological stages were 8 in the IV-stage for lung cancers and 5 in the III- and 1 in the IV-stage for MPM. The profiles of the preoperative patients' characteristics are summarized in Table 1. We divided these 14 cases of IPHC in two groups; the lung cancer group (LC-group) and malignant pleural mesothelioma group (MPM-group), and retrospectively studied the perioperative factors and evaluated the treatment outcomes. The ethics committee in our hospital approved this clinical study.

\subsection{Surgery for IPHC}

We performed IPHC $\left(43^{\circ} \mathrm{C}, 120 \mathrm{~min}, 200 \mathrm{mg} / \mathrm{m}^{2}\right.$ of cisplatin), the therapy of which was based on the modified methods from the previous reports of Matsuzaki et al. [2] [3] (Figure 1 and Figure 2(a), Figure 2(b)), which 
was expected to have a double synergistic effectiveness of the cisplatin-cytotoxic and hyperthermic anti-tumor effects on the tumor cells. Under general anesthesia, after a single lung ventilation, the IPHC was performed under video-assisted thoracic surgery. A thoracovideoscope was inserted into the pleural cavity. Two ports were inserted at the lateral thorax. Two inflow and outflow tubes were placed in the pleural cavity, while a intrapleural thermometer and air-vent tube were inserted in the intrathorax through a port wound for the thoracoscopy, which were connected to a specially devised circuit (modified CRPH-3000C, Mera, Senko Medical instrument Mfg. Co, Ltd., Tokyo, Japan). A $150 \mathrm{mg}$ amount of fosaprepitant megluminein in $100 \mathrm{ml}$ of saline was intravenously dripped for 30 minutes. A $0.75 \mathrm{mg}$ amount of palonosetron hydrochloride and $16 \mathrm{mg}$ of examethasone mixture in $50 \mathrm{ml}$ of saline was intravenously dripped for 10 minutes. These drugs were prophylactically used to treat any nausea and vomiting. The thoracic cavity was irrigated for 2 hours with a $43^{\circ} \mathrm{C}$ saline solution (3000 $\mathrm{ml}$ ) containing $200 \mathrm{mg} / \mathrm{m}^{2}$ of cisplatin (Randa ${ }^{\circledR}$, Nippon Kayaku Co., Ltd., Tokyo, Japan) (Figure 1 and Figure 2). At the end of the perfusion, all fluids in the thoracic cavity were removed. The irrigated thoracic cavity was then washed with saline. When a one-lung-ventilation was converted to a two-lung one, $1 \mathrm{~g}$ of methylprednisolone sodium succinate in $100 \mathrm{ml}$ of saline was intravenously dripped during the expansion of the collapsed lung to

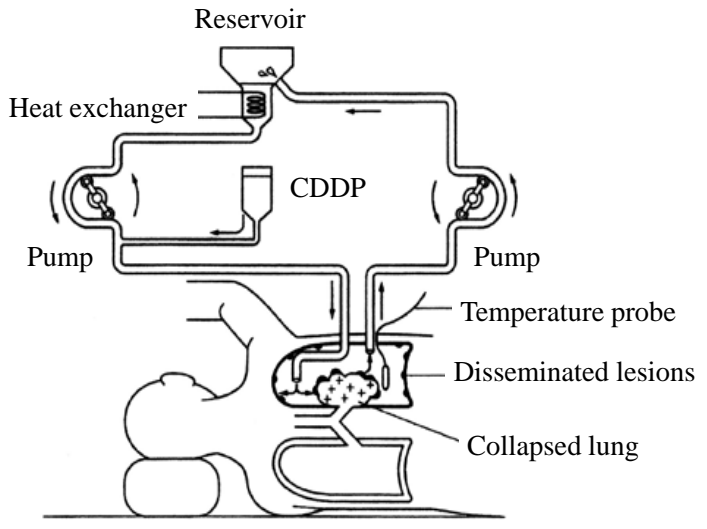

Figure 1. The schema of the IPHC schemes.

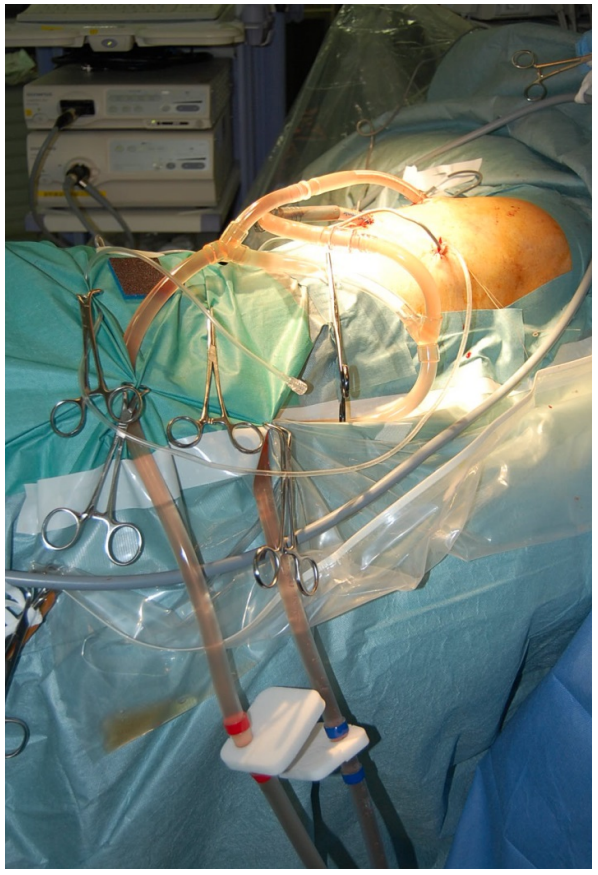

(a)

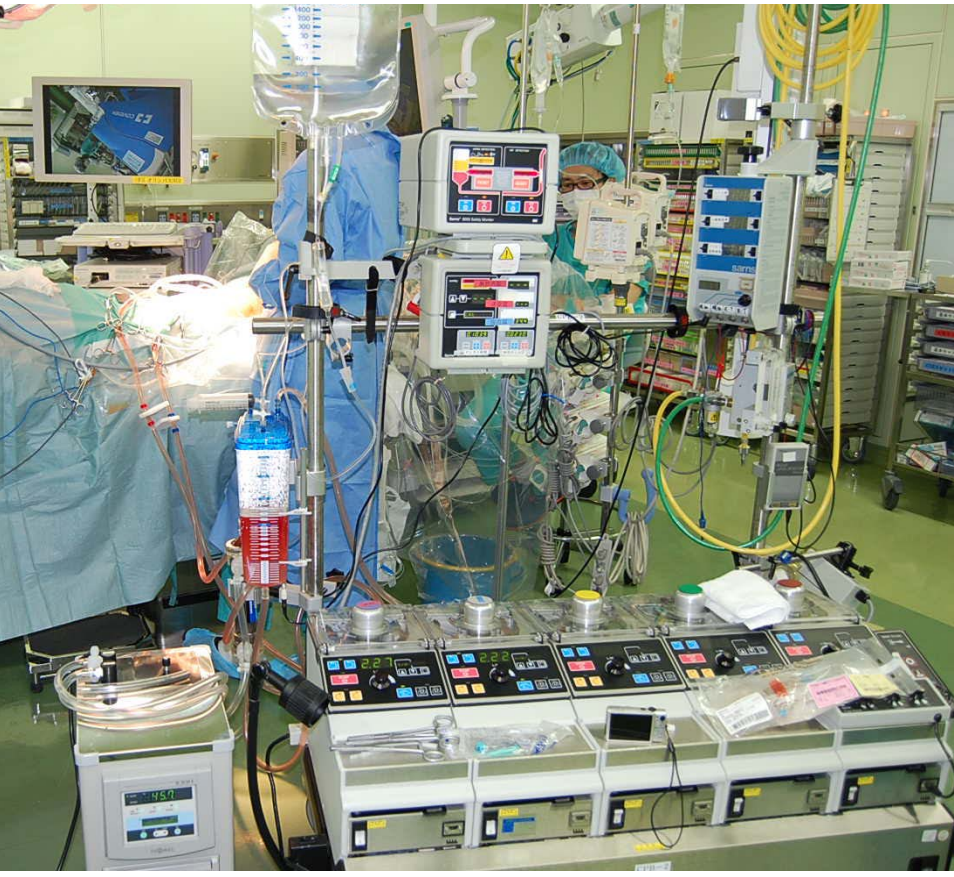

(b)

Figure 2. Intraoperative photo during IPHC treatment. (a) Operative field; (b) IPHC apparatus. 
protect the reperfusion pulmonary injury.

\subsection{Retrospective Analysis of Clinical Data}

We studied the preoperative, intraoperative, and postoperative factors, and evaluated the treatment outcomes regarding the safety and effectiveness of the IPHC. The profiles of the preoperative, intraoperative, and postoperative patients' characteristics are summarized in Table 1, Table 3, and Table 5. As the preoperative factors, age, gender, site, diagnosis, histology, classification, stage, and lung function were analyzed in the two groups.

As the intraoperative factors, regimens of IPHC treatment, operating time, IPHC time, blood loss, blood transfusion, intraoperative urine, intraoperative urine per hour, and intraoperative complication were compared in the two groups. As the postoperative factors, the drain detention period, postoperative complications, and post-treatment therapy were evaluated and compared in the two groups.

\subsection{Adverse Outcomes}

The adverse events were retrospectively examined, which were based on the patient's medical records upon physical examination, toxic effects, and laboratory data of the blood cell counts and blood chemistry. The adverse events and their outcomes were evaluated after completion of the IPHC treatment according to the Common Terminology Criteria for Adverse Events Version 4.0 (CTCAE v4.0). The CTCAE v4.0 displays Grades 1 through 5 with unique clinical descriptions of severity for each adverse event (AE) based on this general guideline: Grade 1, mild AE; Grade 2, moderate AE; Grade 3, severe AE; Grade 4, life-threatening or disabling AE; Grade 5, death related to AE.

\subsection{Evaluation of Effectiveness of IPHC Treatment}

To evaluate the effectiveness of the IPHC treatment, the postoperative status of the pleural effusion was examined. The residual of the malignant cells in the postoperatively drained pleural effusion was diagnosed by postoperative cytology, that is, diagnosed with a negative or positive finding, or defined based on the cytological malignancy classification. Regarding the postoperative accumulated amount of the pleural effusion, as a height from the back chest bottom by chest CT scanning, which was measured, the degree of the accumulated pleural effusion after the IPHC treatment was compared to the preoperative status at the same slice level of the CT scanning and evaluated as reduction, unchanged, or increased. The effectiveness of the IPHC treatment was represented as the rate of the controlled cases of the reduced pleural effusion in all the cases.

\subsection{Statistical Analysis}

The results are presented as the mean standard deviation (SD) or as a percentage. Comparisons of the results between the continuous variables were analyzed using the independent samples $t$ test, and between categorical variables with chi-square statistics. The ethics committee of the University of Miyazaki Hospital approved this protocol.

\section{Results}

\subsection{Outcomes of Preoperative Factors}

Table 1 and Table 2 show the preoperative profiles of the patients and the outcomes of the preoperative factors. Fourteen patients had advanced lung cancer (LC group, $n=8$ ) (IV-staged, 7 adenocarcinomas, 1 pulmonary angiosarcoma) and malignant pleural mesothelioma (MPM group, $\mathrm{n}=6$ ) (epithelial type, III-staged: $\mathrm{n}=5$; IVstaged: $n=1)$. The LC group consisted of advanced lung cancers $(n=4)$, intraoperatively-found dissemination $(n=1)$, and postoperative recurrences $(n=3)$. The patient age averaged $66.5 \pm 11.1$ years old (range, $45-75)$, and there was no significant difference between the two groups $(\mathrm{p}=0.143)$. There were more males $(\mathrm{n}=8)$ than females $(\mathrm{n}=3)$. There were 6 left sided cases and 8 right ones, which showed a significant difference $(\mathrm{p}=$ $0.043)$. The preoperative lung function showed a vital capacity $(2.5 \pm 0.9 \mathrm{~L}$ ), percent of vital capacity (\%VC, $79.2 \pm 20.4 \mathrm{~L}$ ), forced expiratory volume in one second $\left(\mathrm{FEV}_{1}, 1.8 \pm 0.6 \mathrm{~L}\right)$, and $\% \mathrm{FEV}_{1}(76.2 \pm 9.4 \mathrm{~L})$ in all the cases. Based on the spirometer's parameters, there were no significant differences in the two groups. The follow-up period was 27 months (range, 4 to 48 months). 
Table 1. The preoperative profile of the patients.

\begin{tabular}{|c|c|c|c|c|c|c|c|}
\hline Case & Age & Gender & Site & Diagnosis & Histology & Classification & Stage \\
\hline 1 & 73 & M & $\mathrm{R}$ & Advanced LC & Ad & N2M1a & IV \\
\hline 2 & 71 & M & $\mathrm{L}$ & Postoperative recurrence & Ad & N3M1a & IV \\
\hline 3 & 74 & M & $\mathrm{L}$ & Postoperative recurrence & Ad & N2M1a & IV \\
\hline 4 & 59 & M & $\mathrm{R}$ & Intraoperatively-found dissemination & Ad & NxM1a & IV \\
\hline 5 & 68 & M & $\mathrm{R}$ & Advanced LC & Ad & NxM1a & IV \\
\hline 6 & 76 & M & $\mathrm{R}$ & Postoperative recurrence & Ad & N1M1a & IV \\
\hline 7 & 45 & M & $\mathrm{R}$ & Advanced LC & Ad & N1M1a & IV \\
\hline 8 & 48 & M & $\mathrm{L}$ & Advanced LC & $\mathrm{Pa}$ & N2M1a & IV \\
\hline 9 & 60 & M & $\mathrm{L}$ & MPM & Epi & T3N0 & III \\
\hline 10 & 65 & $\mathrm{~F}$ & $\mathrm{~L}$ & MPM & Epi & T3N1 & III \\
\hline 11 & 75 & F & $\mathrm{R}$ & MPM & Epi & T4N2 & IV \\
\hline 12 & 74 & $\mathrm{~F}$ & $\mathrm{~L}$ & MPM & Epi & T3N0 & III \\
\hline 13 & 72 & M & $\mathrm{R}$ & MPM & Epi & T3N0 & III \\
\hline 14 & 71 & M & $\mathrm{R}$ & MPM & Epi & T2N1 & III \\
\hline
\end{tabular}

Case 1 - 8: Lung Cancer group; Case 9 - 14: Malignant pleural mesothelioma group; LC: Lung cancer; Pa: Pulmonary angiosarcoma; Epi: Epithelial; MPM: Malignant pleural mesothelioma; Ad: Adenocarcinoma.

Table 2. Outcomes of the preoperative factors.

\begin{tabular}{|c|c|c|c|c|c|c|}
\hline The preoperative factors & & & $\begin{array}{c}\text { Total } \\
(\mathrm{n}=14)\end{array}$ & $\begin{array}{l}\text { LC group } \\
(\mathrm{n}=8)\end{array}$ & $\begin{array}{l}\text { MPM group } \\
\quad(\mathrm{n}=6)\end{array}$ & $\mathrm{p}$ value \\
\hline \multirow{2}{*}{ Age } & \multicolumn{2}{|l|}{ Mean \pm SD } & $66.5 \pm 11.1$ & $63.7 \pm 13.0$ & $71.5 \pm 4.5$ & 0.143 \\
\hline & \multicolumn{2}{|l|}{ (range) } & $(45-75)$ & $(45-73)$ & $(60-75)$ & \\
\hline \multirow{2}{*}{ Gender } & \multicolumn{2}{|l|}{ Male } & 11 & 8 & 3 & \\
\hline & \multicolumn{2}{|l|}{ Female } & 3 & 0 & 3 & 0.427 \\
\hline \multirow{2}{*}{ Site } & \multicolumn{2}{|l|}{ Left } & 6 & 3 & 3 & \\
\hline & \multicolumn{2}{|l|}{ Right } & 8 & 5 & 3 & 0.043 \\
\hline \multirow{3}{*}{ Histology } & \multirow{2}{*}{ NSCLC } & Ad & 7 & 7 & & \\
\hline & & $\mathrm{Pa}$ & 1 & 1 & & \\
\hline & MPM & Epi & 6 & & 6 & \\
\hline \multirow{3}{*}{ Stage } & NSCLC & IV & 8 & 8 & & \\
\hline & \multirow{2}{*}{ MPM } & III & 5 & & 5 & \\
\hline & & IV & 1 & & 1 & \\
\hline \multirow{4}{*}{ Lung function } & VC (L) & & $2.5 \pm 0.9$ & $2.7 \pm 1.0$ & $2.3 \pm 0.8$ & 0.263 \\
\hline & \%VC (\%) & & $79.2 \pm 20.4$ & $76.3 \pm 21.6$ & $83.1 \pm 19.7$ & 0.154 \\
\hline & $\mathrm{FEV}_{1}(\mathrm{~L})$ & & $1.8 \pm 0.6$ & $1.9 \pm 0.7$ & $1.7 \pm 0.6$ & 0.406 \\
\hline & $\% \mathrm{FEV}_{1}(\%)$ & & $76.2 \pm 9.4$ & $75.7 \pm 12.6$ & $76.9 \pm 3.1$ & 0.454 \\
\hline
\end{tabular}

LC: Lung cancer; MPM: Malignant pleural mesothelioma; Epi: Epithelial; NSCLC: Non-small cell lung cancer; Ad: Adenocarcinoma; Pa: Pulmonary angiosarcoma; VC: Vital capacity; $\mathrm{FEV}_{1}$ : Forced expiratory volume in 1 second. 


\subsection{Outcomes of Intraoperative Factors}

Table 3 shows the intraoperative profile of the patients. Table 4 summarizes the outcomes of the intraoperative factors. IPHC was performed with three regimens of CDDP (300 mg) plus saline $(\mathrm{n}=12)$, CDDP $(100 \mathrm{mg})$ plus saline $(n=1)$, and CDDP (300 mg) plus distilled water $(n=1)$. The operating time was $204 \pm 70$ minutes. The IPHC time was $59 \pm 19$ minutes. The blood loss was $292 \pm 365 \mathrm{ml}$ and a blood transfusion was performed in two cases $(14.3 \%, 2 / 14)$. The amount of intraoperative urine was $1168 \pm 757 \mathrm{ml}$, which was calculated to be 351 $\pm 186 \mathrm{ml} /$ hour. An intraoperative complication was observed in two cases in the LC group as lung injury due to

Table 3. The intraoperative profiles of the patients.

\begin{tabular}{|c|c|c|c|c|c|c|c|c|}
\hline Case & IPHC regimen & $\begin{array}{l}\text { Operative } \\
\text { time }\end{array}$ & $\begin{array}{l}\text { IPHC } \\
\text { time }\end{array}$ & $\begin{array}{l}\text { Blood loss } \\
\quad(\mathrm{ml})\end{array}$ & $\begin{array}{c}\text { Blood } \\
\text { transfusion }\end{array}$ & $\begin{array}{l}\text { Intraoperative } \\
\text { urine (ml) }\end{array}$ & $\begin{array}{l}\text { Urine } \\
(\mathrm{ml}) / \mathrm{hr}\end{array}$ & $\begin{array}{l}\text { Intraoperative } \\
\text { complications }\end{array}$ \\
\hline 1 & CDDP $300 \mathrm{mg}+$ saline & 152 & 30 & 170 & - & 1370 & 541 & Lung injury ${ }^{*}$ \\
\hline 2 & CDDP $300 \mathrm{mg}$ + saline & 80 & 30 & 400 & + & 600 & 450 & - \\
\hline 3 & CDDP $100 \mathrm{mg}+$ saline & 131 & 30 & 550 & - & 990 & 453 & - \\
\hline 4 & CDDP $300 \mathrm{mg}+$ saline & 227 & 90 & 300 & - & 800 & 211 & - \\
\hline 5 & CDDP $300 \mathrm{mg}$ + saline & 288 & 90 & 50 & - & 380 & 79 & Lung injury $^{*}$ \\
\hline 6 & CDDP $300 \mathrm{mg}$ + saline & 169 & 60 & 0 & - & 370 & 131 & - \\
\hline 7 & CDDP $300 \mathrm{mg}+$ saline & 310 & 60 & 180 & - & 1380 & 267 & - \\
\hline 8 & CDDP 300 mg + distilled water & 152 & 60 & 0 & + & 1480 & 584 & - \\
\hline 9 & CDDP $300 \mathrm{mg}$ + saline & 200 & 60 & 0 & - & 970 & 291 & - \\
\hline 10 & CDDP $300 \mathrm{mg}$ + saline & 291 & 70 & 1010 & - & 2860 & 590 & - \\
\hline 11 & CDDP $300 \mathrm{mg}+$ saline & 261 & 60 & 1030 & - & 2150 & 494 & - \\
\hline 12 & CDDP $300 \mathrm{mg}$ + saline & 135 & 60 & 0 & - & 200 & 89 & - \\
\hline 13 & CDDP $300 \mathrm{mg}$ + saline & 230 & 60 & 100 & - & 1950 & 509 & - \\
\hline 14 & CDDP $300 \mathrm{mg}+$ saline & 230 & 60 & 100 & - & 850 & 222 & - \\
\hline
\end{tabular}

Case 1 - 8: Lung cancer group; Case 9 - 14: Malignant pleural mesothelioma group.

Table 4. Outcomes of the intraoperative factors.

\begin{tabular}{|c|c|c|c|c|c|}
\hline $\begin{array}{l}\text { The intraoperative } \\
\text { factors }(n=14)\end{array}$ & & $\begin{array}{c}\text { Total } \\
(n=14)\end{array}$ & $\begin{array}{l}\text { LC group } \\
\quad(n=8)\end{array}$ & $\begin{array}{l}\text { MPM group } \\
\quad(n=6)\end{array}$ & $\mathrm{p}$ value \\
\hline \multirow{3}{*}{ IPHC regimen } & CDDP $300 \mathrm{mg}+$ saline & 12 & 6 & \multirow[t]{3}{*}{6} & \\
\hline & CDDP $100 \mathrm{mg}+$ saline & 1 & 1 & & \\
\hline & CDDP 300 mg + distilled water & 1 & 1 & & \\
\hline Operative time (min) & & $204 \pm 70$ & $189 \pm 80$ & $225 \pm 54$ & 0.211 \\
\hline IPHC time (min) & & $59 \pm 19$ & $56 \pm 25$ & $62 \pm 4$ & 0.313 \\
\hline Blood loss (ml) & & $292 \pm 365$ & $206 \pm 199$ & $428 \pm 542$ & 0.154 \\
\hline \multirow{2}{*}{ Blood transfusion } & + & $2(14.3 \%, 2 / 14)$ & $2(25 \%, 2 / 8)$ & 0 & \multirow{2}{*}{0.147} \\
\hline & - & 12 & 6 & 6 & \\
\hline Intraoperative urine (ml) & & $1168 \pm 757$ & $921 \pm 454$ & $1497 \pm 987$ & 0.058 \\
\hline Intraoperative urine (ml/hour) & & $351 \pm 186$ & $340 \pm 192$ & $366 \pm 195$ & 0.317 \\
\hline Intraoperative complication & Lung injury ${ }^{*}$ & 2 & 2 & 0 & 0.147 \\
\hline
\end{tabular}

IPHC: Intrapleural hyperthermic chemotherapy; "Pleural adhesion. 
exfoliation of the pleural adhesion. These parameters of the intraoperative factors showed no significant difference between the two groups.

\subsection{Outcomes of Postoperative Factors}

Table 5 shows the postoperative profiles of the patients. Table 6 displays the outcomes of the postoperative factors. The drain detention period was $9.9 \pm 3.1$ day. There was no significant difference in the two groups $(\mathrm{p}=$ 0.453). Regarding the postoperative complication related to the IPHC surgery, subcutaneous emphysema was observed in one case as a grade 2 air leak due to pulmonary fistula $(7.1 \%, 1 / 14)$. A postoperative complication was significantly observed in the LC group $(1 / 8,12.5 \%)$ compared to the MPM group $(0 / 8,0 \%)(p=0.040)$. Regarding the post-treatment therapies of the 14 cases, Table 5 shows the post-treatment profiles. After the IPHC treatment, nine cases received post-treatment after the IPHC, not only the IPHC, but also the post-therapy had been performed in nine cases $(64.3 \%, 9 / 14)$, which was chemotherapy and/or molecular-targeted drug therapy.

\subsection{Outcomes of Toxicity and Safety}

Table 7 shows the profile of the toxicities for the fourteen IPHC cases. Table 8 summarizes the adverse outcomes of the IPHC and the comparison between the two groups. Regarding the hematological toxicity of the

Table 5. The postoperative profiles of the patients.

\begin{tabular}{cccc} 
Case & $\begin{array}{c}\text { Drain detention } \\
\text { period (day) }\end{array}$ & $\begin{array}{c}\text { Postoperative } \\
\text { complications }\end{array}$ & Post-treatment therapy \\
\hline 1 & 8 & - & GEM + CBDCA \\
2 & 10 & - & Gefitinib \\
3 & 12 & - & Gefitinib, Vinorelbine \\
4 & 9 & Air leak & Gefitinib \\
5 & 8 & - & - \\
6 & 13 & - & Docetaxel, Chemotherapy \\
7 & 6 & - & - \\
8 & 14 & - & CPT-11 + Epirubicin \\
\hline 9 & 8 & - & CPT-11 + Epirubicin, GEM + CBDCA \\
10 & 14 & - & - \\
12 & 14 & - & CDDP (50 mg) + OK432 (5KE), Irinotecan + Epirubicin \\
\hline 13 & 8 & - & - \\
\hline
\end{tabular}

*Subcutaneous emphysema.

Table 6. Outcomes of the postoperative factors.

\begin{tabular}{|c|c|c|c|c|c|}
\hline $\begin{array}{l}\text { The postoperative factors } \\
\qquad(\mathrm{n}=14)\end{array}$ & & $\begin{array}{c}\text { Total } \\
(n=14)\end{array}$ & $\begin{array}{l}\text { LC group } \\
(\mathrm{n}=8)\end{array}$ & $\begin{array}{l}\text { MPM group } \\
\quad(n=6)\end{array}$ & $\mathrm{p}$ value \\
\hline Drain detention period (day) & & $9.9 \pm 3.1$ & $10.0 \pm 2.8$ & $9.8 \pm 4.0$ & 0.453 \\
\hline \multirow{2}{*}{ Postoperative complications ${ }^{*}$} & - & 13 & 7 & 6 & \\
\hline & + & $1(7.1 \%, 1 / 14)$ & $1(12.5 \%, 1 / 8)$ & 0 & 0.040 \\
\hline
\end{tabular}

${ }^{*}$ Pulmonary fistula (G2). 
IPHC, which was observed in one case of hematological toxicity of more than grade 3 in total $(7.1 \%, 1 / 14)$. In the LC group, there was one case of grade 3 anemia $(25 \%, 1 / 8)$, which was significantly observed in the LG group compared to that in the MPM group $(0 \%, 0 / 6)(\mathrm{p}=0.040)$. Regarding the grade 2 hematological toxicity of neutropenia, there was one case in the LC group $(25 \%, 1 / 8)$, which was also significantly observed in the LG groups compared to that in the MPM group $(0 \%, 0 / 6)(\mathrm{p}=0.040)$. Regarding the grade 2 anemia, there was four cases in total $(28.6 \%, 4 / 14), 2$ cases were observed in the LC group and the others in the MPM group ( $\mathrm{p}=$ 0.107). On the other hand, there were no non-hematological toxicities of more than grade 3 . There was observed in three cases of grade 2 appetite loss $(50 \%, 3 / 6)$ and three cases of grade $2(50 \%, 3 / 6)$ in the MPM group.

\subsection{Effectiveness of IPHC Treatment and Control of Pleural Effusion}

Table 9 shows the profile of the postoperative cytological results and evaluation of the amount of pleural effusion after the IPHC. Table 10 displays the treatment outcomes of the IPHC. We evaluated the effectiveness of the IPHC treatment based on the results of the postoperative cytology of pleural effusion at the removal of the

Table 7. The postoperative toxicity profiles of the patients.

\begin{tabular}{|c|c|c|c|c|c|c|c|c|}
\hline \multirow{2}{*}{ Case } & \multicolumn{4}{|c|}{ Hematological toxicitites } & \multicolumn{4}{|c|}{ Non-hematological toxicities } \\
\hline & Neutropenia & Anemia & Thrombocytopenia & Appetite loss & Nausea & Vomitting & Diarrhea & $\begin{array}{c}\text { Liver } \\
\text { dysfunction }\end{array}$ \\
\hline 1 & - & G1 & - & - & - & - & - & - \\
\hline 2 & G2 & G3 & - & - & - & - & - & - \\
\hline 3 & - & G2 & - & - & - & - & - & - \\
\hline 4 & - & G1 & - & - & - & - & - & - \\
\hline 5 & - & G1 & - & - & - & - & - & - \\
\hline 6 & - & G1 & - & - & - & - & - & - \\
\hline 7 & G1 & G1 & - & - & - & - & - & - \\
\hline 8 & - & G2 & - & - & - & - & - & G1 \\
\hline 9 & - & - & - & - & - & - & - & G1 \\
\hline 10 & - & G2 & - & G2 & G2 & - & - & - \\
\hline 11 & - & G2 & - & G2 & G2 & - & - & G1 \\
\hline 12 & - & G1 & - & - & - & - & - & - \\
\hline 13 & - & G1 & - & G2 & G2 & - & - & G1 \\
\hline 14 & - & G1 & - & - & - & - & - & G1 \\
\hline
\end{tabular}

Case 1 - 8: Lung cancer group; Case 9 - 14: Malignant pleural mesothelioma group.

Table 8. A comparison of the adverse outcomes of the patients.

\begin{tabular}{|c|c|c|c|c|}
\hline Adverse events & $\begin{array}{c}\text { Total } \\
(n=14)\end{array}$ & $\begin{array}{l}\text { LC group } \\
(\mathrm{n}=8)\end{array}$ & $\begin{array}{l}\text { MPM group } \\
\quad(n=6)\end{array}$ & $\mathrm{p}$ value \\
\hline Hematological toxicities ( $\geq \mathrm{G} 3$ ) & $1(7.1 \%, 1 / 14)$ & $1(25 \%, 1 / 8)$ & $0(0 \%, 0 / 6)$ & 0.040 \\
\hline Neutropenia (G2) & 1 & 1 & 0 & 0.040 \\
\hline Anemia (G3) & 1 & 1 & 0 & 0.040 \\
\hline Anemia (G2) & 4 & 2 & 2 & 0.107 \\
\hline Non-hematological toxicities ( $\geq \mathrm{G} 3$ ) & 0 & 0 & & \\
\hline Appetite loss (G2) & 3 & & 3 & 0.384 \\
\hline Nausea (G2) & 3 & & 3 & 0.384 \\
\hline
\end{tabular}


Table 9. The postoperative profiles of cytology and pleural effusion after IPHC.

\begin{tabular}{cccc}
\hline Case & Postoperative cytology & Control of malignant cells & Amount of pleual effusion \\
\hline 1 & Class IIIb & + & Reduction \\
2 & Not performed & - & Unchanged \\
3 & Class III & + & Reduction \\
4 & Negative & - & Reduction \\
5 & Positive & - & Unchanged \\
6 & Positive & - & Reduction \\
7 & Class V & not evaluated & Rot evaluated \\
8 & Negative & + & Reduction \\
9 & Negative & + & Reduction \\
10 & Class II & - & Reduction \\
11 & Class III & + & Reduction \\
12 & Negative & - & Unchanged \\
13 & Class V & - & Reduction \\
14 & Class IV & &
\end{tabular}

Case 1 - 8: Lung cancer group; Case 9 - 14: Malignant pleural mesothelioma group.

Table 10. The treatment outcomes of IPHC.

\begin{tabular}{lccccc}
\hline \multicolumn{1}{c}{ Evaluation items } & Negative & $\begin{array}{c}\text { Total } \\
(\mathrm{n}=14)\end{array}$ & $\begin{array}{c}\text { LC group } \\
(\mathrm{n}=8)\end{array}$ & $\begin{array}{c}\text { MPM group } \\
(\mathrm{n}=6)\end{array}$ & p value \\
\hline \multirow{3}{*}{ Cytology of pleural effusion } & Positive & 7 & 3 & 3 \\
& Not evaluated & 1 & 4 & & 0.083 \\
Control rate of malignant cells & & $46.2 \%(6 / 13)$ & $42.9 \%(3 / 7)$ & $50.0 \%(3 / 6)$ & 5 \\
Postoperative pleural effusion & Reduction & 10 & 5 & 1 & \\
& Unchanged & 3 & 1 & & 0.042 \\
\hline
\end{tabular}

chest drain, and by the measurement of the amount of pleural effusion at the same slice level of chest CT scanning, and by the status of the malignant cells in the pleural effusion after the IPHC treatment. The cytology of the malignant cells in the pleural effusion resulted in a negative $(n=6)$, positive $(n=7)$, and not evaluated ( $n=$ 1). The control rate of the malignant cells was calculated to be $46.2 \%(6 / 13)$. There was no significant difference between the two groups ( $p=0.083$ ), that is, $42.9 \%(3 / 7)$ in the LC group and $50.0 \%(3 / 6)$ in the MPM group. For the assessment of the postoperative amounts of the pleural effusion, the levels were reduction $(\mathrm{n}=10)$, unchanged $(n=3)$, and not evaluated $(n=1)$. The control rate of the pleural effusion was calculated to be $76.9 \%$ (10/13). There was a significant difference between the two groups ( $p=0.042)$, that is, $71.4 \%(5 / 7)$ in the LC group and $83.3 \%$ (5/6) in the MPM group.

\section{Discussion}

In 2010, the Japan Lung Cancer Society, the Japanese Association for Chest Surgery, and the Japanese Associa- 
tion for Thoracic Surgery performed a survey of the lung cancers surgically resected in 2004 [6]. The total number of cases was 11,663 and the overall 5-year survival was $69.6 \%$, which was based on the data accumulated from 253 facilities (41.8\%) in board certified chest surgeon training 605 institutes. The 5-year survival of the clinical stage IV $(\mathrm{n}=434)$ in the Union for International Cancer Control (UICC, ver 7, 2009) was 27.9\%, which accounted for the percentage of 3.7, the pleural dissemination was recognized in 247 cases (2.1\%), and the malignant pleural effusion (positive cytology of effusion) was present in 170 cases (1.5\%). Based on these data from Japan, the cases of preoperatively resectable lung cancer, at least with a degree of 1 to $2 \%$ of which were inferred to be included in the malignant pleural effusion with dissemination, and also in the groups of the seventy thousand dead lung cancer patients every year.

The recent intensive chemotherapy for advanced non-small cell lung carcinoma has been performed using the platinum doublet regimen, which is an effective treatment that showed an extended survival confirmed by the evidence of some meta-analyses [7] [8]. In the 1990s, the new $3^{\text {rd }}$-generation anti-cancer drugs were developed, which included navelbine, paclitaxel, docetaxel, gemcitabine, and pemetrexed. These key new drugs were clinically used in combination with cisplatin or carboplatin. The effectiveness of these platinum doublet therapies has been reported, which is used in combinations therapy that have become the standard treatment regimens for advanced non-small cell lung cancer [9].

The extended survival of advanced lung cancer patients has become 3 times (more than 2 - 3 years) longer than ever, and symptom-management of carcinomatosis pleuritis and malignant pleural effusion have become an important issue. IPHC would be one of the optimal palliative therapies used to improve the QOL for untreatable advanced cancer. As one of the multimodal therapies, IPHC should be one of the most expected modalities for an aggressive palliation therapy such as intrathoracic local control of the tumor, control of the pleural effusion, and preserving the good QOL during survival.

The targeted cases of this IPHC treatment were thoracic malignances with dissemination such as unresectable advanced lung cancer with malignant effusion along with carcinomatous pleuritis, intrathoracic recurring cases after primary lung cancer surgery, MPM, sarcoma tumors, metastatic intrapleural tumors due to breast and colon cancers, and other cancers. We introduced the use of IPHC for special diseases except lung cancer, which was disseminated intrapleural angiosarcoma and there was no effective chemotherapeutic treatment except surgery. We performed a palliative pneumonectomy of the unresectable pulmonary angiosarcoma [5], the case of which is listed as No. 8 in Table 1, Table 3, and Table 5. The reason for this was to reduce the angiosarcoma volume and to prevent lethal pulmonary bleeding from the tumor. Because there were few effective therapies for pulmonary angiosarcoma, we selected a combination therapy of palliative surgical resection and intrapleural hypotonic hyperthermic chemotherapy (IPHHC). For the residual disseminated intrathoracic sarcoma cells, as a local intrathoracic therapy, in addition to the effect of the hyperthermic damage and sarcoma-cell cell injury, we used the perfusion solution of distilled water. During the postoperative hospitalization, there was no memorable adverse event of more than grade 3. The patient's survival after the treatment was 21 months, thus as a palliative and intrapleural local therapy for thoracic malignancies with pleural effusion, the IPHHC therapy should be one of the considered therapies.

The theory and mechanism of the effectiveness of the IPHC is described below. The anti-cancer effectiveness of hyperthermia are generally denoted as, 1) tumor cells have a high hyperthermic sensitivity compared to those of normal cells, 2) tumor tissue has a high hyperthermic sensitivity selectively dependent on the specificity of the surrounding tissue-environment (low $\mathrm{pH}$, hypoxic, fragility of tumor angiogenesis), 3) a high hyperthermic sensitivity in the latter phase of the synthesis in the cell cycle, and 4) enhancement of the sensitivity of the anticancer drug for cancer cells, which had been performed as a combination therapy with radiation and chemotherapy.

Regarding the concentration of cisplatin in the tumor tissue, the local administered method showed a 2- to 3 -fold higher level compared to that of the intravenously dripped infusion [10]. Depending on the above administration methods, there was no difference in the concentration of cisplatin in the center of the tumor tissue. However, regarding the infiltration of cisplatin inside the tumor, at the normal body temperature, the cisplatin could enter to a depth of 1 to $2 \mathrm{~mm}$ inside the tumor tissue [11] [12]. If the infiltrated rate of cisplatin was 1-fold at $37^{\circ} \mathrm{C}$, it becomes 4 -fold at $40^{\circ} \mathrm{C}$ and 6 -fold at $43^{\circ} \mathrm{C}$. Depending on the body temperature, the infiltration of cisplatin increases and has a much greater cytotoxic effect. For the infiltrated depth of cisplatin, which could infiltrate to a depth of $1.5 \mathrm{~mm}$ into the tumor tissue at $37^{\circ} \mathrm{C}$ and to a depth of $5 \mathrm{~mm}$ at $42^{\circ} \mathrm{C}$, which was a 4 -fold increase [13]. 
No updated evidence has recently been reported by a restrictive clinical trial regarding the therapy of IPHC. A conventional IPHC is a monotherapy of the hyperthermic perfusion of cisplatin into the intrathoracic cavity, which had been performed as a treatment for thoracic malignant diseases with dissemination in clinical practice. To manage the malignant pleural effusion, there were some methods, which were known as a repetition of the intrapleural drainage puncture, pleurodesis with a chest tube and thoracoscopy, detention of the intrapleural catheter tube, an intrapleuroperitoneal shunt, pleurectomy, intrapleural hypotonic cisplatin lavage, and our conventional IPHC treatment.

For the unresectable advanced and terminal staged patients with carcinomatosis pleuritis with malignant pleural effusion, the objective was to reduce the worse symptoms of dyspnea, which decreased the QOL of the patient. In this situation, there were many intrathoracic punctures and/or intrapleural drainage for palliation of the symptoms. Even though the patient was discharged with palliation of the clinical symptoms, however, because of re-accumulation of the pleural effusion, repeated management of pleural effusion should be needed. The patient's QOL and activity of daily living have become worse, resulting in extended hospitalization and shortening of being at home. Regarding the benefit of IPHC treatment, even though this therapy has a surgical invasive aspect, however, not only the hyperthermic and anticancer effectiveness but also the palliation of dyspnea-symptoms and improvement of the QOL occurred. The efficacy of the IPHC treatment has an effect on the control of the pleural effusion, shortening of the drain detention period, and extension of outpatient care, that resulted in preserving of the patient's good QOL.

In the past, our study group reported the first outcome of the IPHC treatments for thoracic malignant diseases with pleural dissemination with effusion, which were performed from 1988 to $1993(n=12)$ [2], the median survival time in the group of the IPHC $(n=12)$ being 20 months. On the other hand, the median survival time in the control group $(\mathrm{n}=7)$ was 6 months [2]. Regarding the next outcome of our IPHC treatments for lung cancers with pleural dissemination with effusion, which were performed from 1994 to $2004(n=11)$ [3], the median survival time of the IPHC group $(\mathrm{n}=11)$ was 20 months. On the other hand, the median survival time of the control group $(n=11)$ was 6 months, thus there was a significant difference $(p<0.05)$ [3]. The ratio of spontaneous apoptosis of untreated tumor cells was $2.8 \% \pm 2.0 \%$. Following the perfusion, apoptosis among the tumor cells was $25.2 \% \pm 4.6 \%$, clearly a significant increase $(\mathrm{p}<0.001)$. IPHC increases apoptosis in the malignant pleuritis [3]. Matsuzaki et al. [4] studied the induction of apoptosis by IPHC for the MPM. Our IPHC treatment was performed on 6 consecutive patients with MPM (stage III: 5; staga IV: 1). Preperfusion, the apoptosis index was $3.8 \% \pm 2.0 \%$, indicating spontaneous apoptosis of the untreated tumor cells. Postperfusion, the apoptosis index at 0,24 , and 48 hours was $22.8 \% \pm 5.2 \%, 63.8 \% \pm 8.2 \%$, and $47.8 \% \pm 6.9 \%$, respectively. The patient had a median survival time of 30 months and no patient's morbidity was associated with the perfusion treatment.

Regarding the limitation of our present study, we recognized the small sample size, the non-prospective study, the retrospective analysis of the old medical records, no evaluation of long-term outcomes, such as overall survival, assessment of short-term outcomes, such as cytology and amount of pleural effusion, no evaluation of the QOL outcome, and no study of the effectiveness of any post-treatment treatment.

Recently, there has not been a distinct clinical phase-II study and no update as new evidence of the IPHC treatment. The regimen has become the old-fashioned single use of cisplatin and its hyperthermic perfusion of the intrapleural space. A new next-generation IPHC and its accurate evidence should be expected. We developed a new next-generation IPHC, whose regimen is constructed of platinum doublet chemotherapy with the new $3^{\text {rd }}$ generation cytotoxic drugs, that is, the additional oral medication of a S-1 drug. As the optimal aggressive palliation therapy, our new clinical trial, the next-generation IPHC is a hybrid chemotherapy combined with oral S-1 medication plus conventional cisplatin-based IPHC for the advanced thoracic malignancies with pleural effusion. We have reported the first case, and its preliminary feasibility, safety, efficacy, and good preserving of the QOL [14]. Furthermore, we have been compiling our experiences and cases of the new-generation IPHC treatment, and will report new evidence in the near future, which would be to establish the optimal aggressive palliative therapy.

\section{Conclusion}

IPHC treatment resulted in no major complications, fewer adverse events of more than grade 3, which we could safely perform. We obtained a high effectiveness of the IPHC treatment, which resulted in both a high posttreatment control rate of pleural effusion (76.9\%) and a control rate of malignant cells in the pleura effusion (46.2\%). 


\section{Acknowledgements}

This study was supported by a Grant-in-Aid for Clinical Research from the Miyazaki University Hospital.

\section{References}

[1] Goldstraw, P., Crowley, J., Chansky, K., Giroux, D.J., Groome, P.A., Rami-Porta, R., Postmus, P.E., Rusch, V., Sobin, L., International Association for the Study of Lung Cancer International Staging Committee, Participating Institutions (2007) The IASLC Lung Cancer Staging Project: Proposals for the Revision of the TNM Stage Groupings in the Forthcoming (Seventh) Edition of the TNM Classification of Malignant Tumours. Journal of Thoracic Oncology, 2, 706-714. http://dx.doi.org/10.1097/JTO.0b013e31812f3c1a

[2] Matsuzaki, Y., Shibata, K., Yoshioka, M., Inoue, M., Sekiya, R., Onitsuka, T., Iwamoto, I. and Koga, Y. (1995) Intrapleural Perfusion Hyperthermo-Chemotherapy for Malignant Pleural Dissemination and Effusion. The Annals of Thoracic Surgery, 59, 127-131. http://dx.doi.org/10.1016/0003-4975(94)00614-D

[3] Matsuzaki, Y., Edagawa, M., Shimizu, T., Hara, M., Tomita, M., Ayabe, T. and Onitsuka, T. (2004) Intrapleural Hyperthermic Perfusion with Chemotherapy Increases Apoptosis In malignant Pleuritis. The Annals of Thoracic Surgery, 78, 1769-1772. http://dx.doi.org/10.1016/j.athoracsur.2004.05.025

[4] Matsuzaki, Y., Tomita, M., Shimizu, T., Hara, M., Ayabe, T. and Onitsuka, T. (2008) Induction of Apoptosis by Intrapleural Perfusion Hyperthermo-Chemotherapy for Malignant Pleural Mesothelioma. Annals of Thoracic and Cardiovascular Surgery, 14, 161-165.

[5] Ayabe, T., Tomita, M., Chosa, E., Kawagoe, K. and Nakamura, K. (2015) Pneumonectomy of Primary Pulmonary Angiosarcoma with Malignant Effusion and Intrapleural Hypotonic Hyperthermic Chemotherapy: Case Report and Review of the Literature. Journal of Cancer Therapy, 6, 227-236. http://dx.doi.org/10.4236/jct.2015.62025

[6] Japanese Joint Committee for Lung Cancer Registration, Sawabata, N., Fujii, Y. Asamura, H., Nomori, H., Nakanishi, Y., Eguchi, K., Mori, M., Okumura, M., Miyaoka, E. and Yokoi, K. (2004) Lung Cancer in Japan: Analysis of Lung Cancer Registry Cases Resected in 2004. Japanese Journal of Lung Cancer, 50, 875-888. (In Japanese)

[7] Non-Small Cell Lung Cancer Collaborative Group (1995) Chemotherapy in Non-Small Cell Lung Cancer: A MetaAnalysis Using Updated Data on Individual Patients from 52 Randomised Clinical Trials. BMJ, 311, 899-909. http://dx.doi.org/10.1136/bmj.311.7010.899

[8] Marino, P., Pampallona, S., Preatoni, A., Cantoni, A. and Invernizzi, F. (1994) Chemotherapy vs Supportive Care in Advanced Non-Small-Cell Lung Cancer. Results of a Meta-Analysis of the Literature. Chest, 106, 861-865. http://dx.doi.org/10.1378/chest.106.3.861

[9] Wozniak, A.J., Crowley, J.J., Balcerzak, S.P., Weiss, G.R., Spiridonidis, C.H., Baker, L.H., Albain, K.S., Kelly, K., Taylor, S.A., Gandara, D.R. and Livingston, R.B. (1998) Randomized Trial Comparing Cisplatin with Cisplatin Plus Vinorelbine in the Treatment of Advanced Non-Small-Cell Lung Cancer: A Southwest Oncology Group Study. Journal of Clinical Oncology, 16, 2459-2465.

[10] Los, G., Mutsaers, P.H., Lenglet, W.J., Baldew, G.S. and McVie, J.G. (1990) Platinum Distribution in Intraperitoneal Tumors after Intraperitoneal Cisplatin Treatment. Cancer Chemotherapy and Pharmacology, 25, 389-394. http://dx.doi.org/10.1007/BF00686048

[11] Los, G., Sminia, P., Wondergem, J., Mutsaers, P.H., Havemen, J., ten Bokkel Huinink, D., Smals, O., Gonzalez-Gonzalez, D. and McVie, J.G. (1991) Optimisation of Intraperitoneal Cisplatin Therapy with Regional Hyperthermia in Rats. European Journal of Cancer, 27, 472-477. http://dx.doi.org/10.1016/0277-5379(91)90389-U

[12] Los, G., van Vugt, M.J. and Pinedo, H.M. (1994) Response of Peritoneal Solid Tumours after Intraperitoneal Chemohyperthermia Treatment with Cisplatin or Carboplatin. British Journal of Cancer, 69, 235-241. http://dx.doi.org/10.1038/bjc.1994.45

[13] Fujimoto, S., Takahashi, M., Kobayashi, K., Nagano, K., Kure, M., Mutoh, T. and Ohkubo, H. (1992) Cytohistologic Assessment of Antitumor Effects of Intraperitoneal Hyperthermic Perfusion with Mitomycin C for Patients with Gastric Cancer with Peritoneal Metastasis. Cancer, 70, 2754-2760. http://dx.doi.org/10.1002/1097-0142(19921215)70:12<2754::AID-CNCR2820701205>3.0.CO;2-A

[14] Ayabe, T., Tomita, M., Chosa, E., Mori, K. and Nakamura, K. (2016) Outcomes of Quality of Life Regarding the NextGeneration Thoracoscopic Intrapleural Hyperthermic Chemotherapy of Non-Small Cell Lung Cancer with Dissemination. Journal of Cancer Therapy, 7, 63-77. http://dx.doi.org/10.4236/jct.2016.71008 


\section{Abbreviations}

IPHC: Intrapleural Hyperthermic Chemotherapy

LC: Lung Cancer

MPM: Malignant Pleural Mesothelioma

CDDP: Cisplatin

TNM: Tumor-Node-Metastasis

QOL: Quality of Life 